\title{
worldview
}

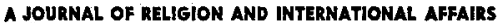

\section{PRINCIPLES, POWER AND EXPEDIENCY}

Whatever the events of the future, the Cuban blockade will be, for a long time to come, a subject of discussion and debate. And a proper subject it is. It was, first, a sharply focussed event. (Like all human events it developed from causes we can endlessly explore and it will have consequences we cannot yet foresee. Yet we can, with greater ease than is ordinarily possible, regard the blockade as an historically discrete and accomplished act.) It had a beginning and an end.

Further, the major factors involved were those we believe, mistakenly or not, that we can comprehend. There were the two great and opposing powers, the USSR and the United States; there was the island of Castro's Cuba; and there was the secret employment of missile bases on that island by the USSR. These factors merged to produce the problem that was solved, at least temporarily, by the blockade imposed unilateralJy by the United States.

In its bluntest form, the question raised by this action is whether the blockade was justified politically or morally. And if so, what are the grounds of the justification. But the question can be posed in other ways, and in ways that frequently suggest their own answer. For example; one person who commented on the Cuban affair wrote:

"The issue is whether this country does not stand for some kind of common law among nations, some kind of distillation of Justice-whether written or not and no matter how loosely defined-which the generality of men recognize; or do we believe, as we allege of the enemy, in power only? If the former is true, then the act of war in Cuban waters is clearly a violation of our deepest principles; if the latter is true, then there is no such thing as an ideological struggle. . . . We cannot have it both ways."

We are here offered the hard alternatives-we must choose either Justice or power, we must either condemn the blockade or support it. There is to be here no obfuscation, no blurring of lines, no sops for the political conscience. Many people see the issue in exactly these terms and have had the courage to make the choice. Faced with the alternatives of power and Justice they have chosen Justice and have condemned the blockade. Others, with equal integrity, forced to choose between condemning the blockade or supporting it have chosen the latter. In this equation they have also and inevitably chosen to tread the path of power.

But we can fairly ask whether this is an inevitable equation. It would certainly place in an uncomfortable and discreditable limbo those who say they choose both Justice and the blockade-and without abjuring the use of power. Are fhese people simply trying to have it both ways? No, the fault lies, rather, with the positing of cruel and unreal alternatives, with the dubious imposition of abstractions on the gritty surface of actual events.

In his commendation of troops employed in the Cuban crisis, the President said, "Regardless of how persistent our diplomacy may be in activities stretching all around the globe, in the final analysis it rests upon the power of the United States, and that power rests upon the will and courage of our citizens..." This is not a statement of cynicism but a statement which ac knowledges the interdependence of principle and power.

If there is a power morality, i.e., if an objective Justice rigorously pursued has a power of. its own, there is also a morality of power, i.e., power; responsibly employed, not only ensures the life of morality but is itself moral. These considerations by no means solve the issues raised by the Cuban blockade. But they are cautions which preclude many false alternatives; they are a necessary prelude to any meaningful discussion conceming that action. 